Acta Crystallographica Section D

Biological

Crystallography

ISSN 1399-0047

Jacob Lauwring Andersen, ${ }^{\text {a* }}$

Tenna Juul Schrøder, ${ }^{b}$ Søren

Christensen, ${ }^{b}$ Dorthe

Strandbygård, ${ }^{\mathrm{a}}$ Lone Tjener

Pallesen, ${ }^{\mathrm{c}}$ Maria Marta García-

Alai, ${ }^{a}$ Samsa Lindberg, ${ }^{b}$ Morten

Langgård, børgen Calí

Eskildsen, ${ }^{\mathrm{b}}$ Laurent David, ${ }^{\mathrm{b}}$ Lena

Tagmose, ${ }^{\mathrm{b}}$ Klaus Baek

Simonsen, ${ }^{\text {b Philip James Maltas, }}$, Lars Christian Biilmann Rønn, ${ }^{b}$ Inge E. M. de Jong, ${ }^{b}$ Ibrahim John Malik, ' Jan Egebjerg, 'bens-Jacob Karlsson, brinivas Uppalanchi, ${ }^{d}$ Durga Rao Sakumudi, ' Pradheep Eradi, $^{\text {d }}$ Steven P. Watson ${ }^{\mathrm{b} *}$ and Søren Thirup ${ }^{\mathrm{a} *}$

${ }^{\mathbf{a}}$ The Lundbeck Foundation Research Centre MIND, Department of Molecular Biology and Genetics, Aarhus University, Gustav Wieds Vej 10C, 8000 Aarhus C, Denmark, beuroscience Drug Discovery, H. Lundbeck A/S, Ottiliavej 9, 2500 Valby, Denmark, 'The Lundbeck Foundation Research Centre MIND, Department of Biomedicine, Aarhus University, Ole Worms Allé 3, 8000 Aarhus C, Denmark, and ${ }^{d}$ Medicinal Chemistry, GVK BioScience, Plot No. 28 A, IDA Nacharam, Hyderabad 500076 , India

Correspondence e-mail: jla@mb.au.dk, stwa@lundbeck.com, sth@mb.au.dk

\title{
Identification of the first small-molecule ligand of the neuronal receptor sortilin and structure determination of the receptor-ligand complex
}

Sortilin is a type I membrane glycoprotein belonging to the vacuolar protein sorting 10 protein $(\mathrm{Vps} 10 \mathrm{p})$ family of sorting receptors and is most abundantly expressed in the central nervous system. Sortilin has emerged as a key player in the regulation of neuronal viability and has been implicated as a possible therapeutic target in a range of disorders. Here, the identification of AF40431, the first reported small-molecule ligand of sortilin, is reported. Crystals of the sortilin-AF40431 complex were obtained by co-crystallization and the structure of the complex was solved to $2.7 \AA$ resolution. AF40431 is bound in the neurotensin-binding site of sortilin, with the leucine moiety of AF40431 mimicking the binding mode of the C-terminal leucine of neurotensin and the 4-methylumbelliferone moiety of AF40431 forming $\pi$-stacking with a phenylalanine.

\section{Introduction}

Sortilin is a $100 \mathrm{kDa}$ type I membrane glycoprotein belonging to the vacuolar protein sorting 10 protein (Vps10p) receptor family. The receptor is composed of a large extracellular domain $(75 \mathrm{kDa})$, a single transmembrane helix and a short cytoplasmic tail (Petersen et al., 1997). The extracellular Vps10p domain is composed of a $\beta$-propeller and a cysteinerich (10CC) domain (Quistgaard et al., 2009). The $\beta$-propeller is composed of ten repeats (blades), forming a wheel-like structure with a funnel-shaped tunnel with a diameter of 25-40 $\AA$ (Fig. 4). Each blade is composed of a four-stranded $\beta$-sheet and is stabilized by an Asp-box repeat in the loop between strands 3 and 4 (Quistgaard \& Thirup, 2009). Sortilin is a key player in the regulation of neuronal viability and function and is widely expressed in the central nervous system (CNS) during development and in adulthood (Petersen et al., 1997; Hermans-Borgmeyer et al., 1999). The receptor is mainly located in intracellular membrane structures (endoplasmic reticulum, trans-Golgi network and endosomal organelles) involved in the sorting of ligands. It has been estimated that a tenth of the cellular sortilin pool is found at the cell surface (Mazella et al., 1998), mediating endocytosis of ligands through clathrin-coated pits (Nielsen et al., 2001). The 13-amino-acid neuropeptide neurotensin (NTS) is a ligand of the G-coupled neurotensin receptors (NTSRs), resulting in dopamine turnover and muscle relaxation, but is also bound by sortilin in the extracellular environment (Munck Petersen et al., 1999). NTS is bound to sortilin in the centre of the tunnel of the $\beta$-propeller and the binding site is composed of a $\beta$-strand interaction between the C-terminus (amino acids 10 13) of neurotensin and strand 1 of blade 6 in sortilin. A strong
Received 2 October 2013 Accepted 4 November 2013

PDB reference: sortilinAF40431 complex, 4msl 
salt bridge is formed between the carboxylic acid of the C-terminus and Arg292 (Quistgaard et al., 2009).

A notable function of sortilin is its role in signalling by neurotrophins, a family consisting of nerve growth factor (NGF), brain-derived neurotrophic factor (BDNF) and neurotrophins 3 and 4 (S-3 and NT-4) in humans. The hallmark of neurotrophin signalling, neuronal survival, is mediated through binding of mature neurotrophin to tyrosine receptor kinases (Trks; Wu et al., 2002). The affinity and specificity of neurotrophin binding is modulated by the presence of the lowaffinity neurotrophin receptor p75 (p75NTR) acting as a coreceptor (Esposito et al., 2001; Hempstead et al., 1991; Bibel et al., 1999). Neurotrophins are expressed with a pro-domain, which is cleaved off in the Golgi, resulting in secretion of the mature domain (Scott et al., 1983). However, the release of unprocessed proneurotrophins results in signalling of apoptosis via p75NTR (Lee et al., 2001) and sortilin (Nykjaer et al., 2004; Teng et al., 2005; Tauris et al., 2011). The mature part of the neurotrophin is bound by p75NTR, whereas the propeptide is bound by sortilin, thereby forming a high-affinity $\left(K_{\mathrm{d}}\right.$ of $\sim 160 \mathrm{p} M$ ) heterotrimeric complex (Nykjaer et al., 2004). Knockout studies have supported the roles of p75NTR (Frade \& Barde, 1999) and sortilin (Jansen et al., 2007) in proneurotrophin-induced apoptosis signalling. Proneurotrophins are released to the extracellular environment in animal models of neurodegenerative conditions, including mechanical damage to the nervous system, focal ischaemia, axotomy, stroke and epileptic seizures (Dechant \& Barde, 2002), and proNGF is detected in vivo for several days following injury (Jansen $e t a l$., 2007). Elevated levels of proNGF (Harrington et al., 2004), p75NTR (Beattie et al., 2002) and sortilin (Jansen et al., 2007) are observed in acute injury models. These upregulations have been suggested to keep the nervous system functional by the clearance of damaged neurons (Lu et al., 2005). Interestingly, elevated levels of proNGF have been identified in patients diagnosed with Alzheimer's disease (Fahnestock et al., 2001). The levels of proneurotrophin in the extracellular environment are controlled by plasmin and matrix metalloproteases (Lee et al., 2001). Elevated levels of inhibitors of the extracellular proteases are found under conditions resembling neurodegenerative diseases (Bruno \& Cuello, 2006).

Outside the CNS, proNGF is overproduced and secreted from malignant breast cancer cells, thereby inducing autocrine stimulation via TrkA and sortilin (Demont et al., 2012), and similar autocrine stimulation has been observed in melanoma cells (Truzzi et al., 2008). Sortilin has further been demonstrated to interact with apolipoprotein B100 in the Golgi and to facilitate the export of apoB100-containing lipoproteins, thereby regulating the levels of low-density lipoprotein (LDL) cholesterol, a key contributor to atherosclerosis and ischaemic heart disease, in plasma (Kjolby et al., 2010).

The interaction between sortilin and the majority of its ligands, including the proneurotrophins, is inhibited by NTS (Nykjaer et al., 2004; Munck Petersen et al., 1999). Hence, a small-molecule ligand mimicking the binding mode of NTS could potentially be applied as a treatment in several disorders in which sortilin has been implicated. Here, we describe the identification of the first small-molecule ligand of sortilin, AF40431, and the structure determination of the receptorligand complex.

\section{Materials and methods}

\subsection{Synthesis and characterization of AF40431 and $1 \mathrm{~h}$}

Compounds 1a-1g were obtained directly from the $\mathrm{H}$. Lundbeck compound collection. AF40431 and 1h were prepared by reductive alkylation and deprotection of L- and D-leucine tert-butyl esters with the corresponding coumarin aldehyde (7-hydroxy-4-methyl-2-oxo- $2 H$-chromene-8-carbaldehyde).

Sodium triacetoxyborohydride $\left[\mathrm{NaBH}(\mathrm{OAc})_{3}\right]$ (1.55 g, $7.34 \mathrm{mmol}$ ) was added to a solution of L-leucine tert-butyl ester hydrochloride $(0.50 \mathrm{~g}, 2.44 \mathrm{mmol})$ and the coumarin aldehyde $(0.68 \mathrm{~g}, 2.93 \mathrm{mmol})$ in dichloroethene (DCE; $50 \mathrm{ml})$ and acetic acid $(0.14 \mathrm{~g}, 2.44 \mathrm{mmol})$ and the reaction mixture was stirred at room temperature for $16 \mathrm{~h}$. Aqueous sodium bicarbonate $\left(\mathrm{NaHCO}_{3}\right)$ solution $(15 \mathrm{ml})$ was added and the mixture was extracted with ethyl acetate $(2 \times 50 \mathrm{ml})$, washed with brine and dried over anhydrous sodium sulfate $\left(\mathrm{Na}_{2} \mathrm{SO}_{4}\right)$. Solvents were removed in vacuo and the crude compound was purified by silica gel (100-200 mesh) column chromatography, eluted with $16 \%$ of ethyl acetate in petroleum ether, to afford the tert-butyl ester of AF40431 (0.37 g, 40\%) as a pale yellow solid. ${ }^{1} \mathrm{H}$ NMR $\left(\mathrm{CDCl}_{3}, 600 \mathrm{MHz}, \mathrm{TMS}\right) \delta: 7.43-7.41(1 \mathrm{H}, \mathrm{d}$, $J=8.7 \mathrm{~Hz}), 6.80-6.78(1 \mathrm{H}, \mathrm{d}, J=8.7 \mathrm{~Hz}), 6.07(1 \mathrm{H}, \mathrm{s}), 4.30$ $4.26(1 \mathrm{H}, \mathrm{d}, J=14.9 \mathrm{~Hz}), 4.18-4.15(1 \mathrm{H}, \mathrm{d}, J=14.9 \mathrm{~Hz}), 3.25-$ $3.23(1 \mathrm{H}, \mathrm{t}, J=7.1 \mathrm{~Hz}), 2.38(3 \mathrm{H}, \mathrm{br} \mathrm{s}), 1.78-1.71(1 \mathrm{H}, \mathrm{sp}$, $J=6.1 \mathrm{~Hz}), 1.56-1.49(2 \mathrm{H}, \mathrm{m}), 1.51(9 \mathrm{H}, \mathrm{s}), 0.95-0.93(3 \mathrm{H}, \mathrm{d}$, $J=6.6 \mathrm{~Hz}), 0.92-0.90(3 \mathrm{H}, \mathrm{d}, J=6.6 \mathrm{~Hz})$.

The tert-butyl ester of AF40431 (0.150 g, $0.39 \mathrm{mmol})$ was taken up in 1:1 dichloromethane (DCM)/trifluoroacetic acid (TFA) $(2 \mathrm{ml})$ and stirred at room temperature for $3 \mathrm{~h}$. The solvents were removed in vacuo and the crude compound was washed with diethyl ether $(2 \times 5 \mathrm{ml})$ and methanol $(2 \times 5 \mathrm{ml})$ and dried in vacuo to afford AF40431 $(0.091 \mathrm{~g}, 72 \%)$ as a white solid. ${ }^{1} \mathrm{H}$ NMR (DMSO-d 6 , $600 \mathrm{MHz}$, TMS) $\delta: 9.95-8.95$ $(1 \mathrm{H}$, br s), $7.58-7.56(1 \mathrm{H}, \mathrm{d}, J=8.8 \mathrm{~Hz}), 6.82-6.80(1 \mathrm{H}, \mathrm{d}$, $J=8.8 \mathrm{~Hz}), 6.15(1 \mathrm{H}, \mathrm{s}), 4.14-4.10(1 \mathrm{H}, \mathrm{d}, J=14.4 \mathrm{~Hz}), 4.04-$ $4.00(1 \mathrm{H}, \mathrm{d}, J=14.4 \mathrm{~Hz}), 3.27-3.22(1 \mathrm{H}, \mathrm{m}), 2.37(3 \mathrm{H}, \mathrm{s}), 1.78$ $1.71(1 \mathrm{H}, \mathrm{sp}, J=6.5 \mathrm{~Hz}), 1.53-1.43(2 \mathrm{H}, \mathrm{m}), 0.89-0.87(3 \mathrm{H}, \mathrm{d}$, $J=6.5 \mathrm{~Hz}), 0.86-0.84(3 \mathrm{H}, \mathrm{d}, J=6.5 \mathrm{~Hz})$. Mass spectrum: $\mathrm{tR}=$ $0.50 \mathrm{~min}, \mathrm{~m} / z=320.0(M+\mathrm{H})^{+}$.

Compound $\mathbf{1 h}$ was prepared in an analogous manner to AF40431, starting from D-leucine tert-butyl ester hydrochloride. ${ }^{1} \mathrm{H}$ NMR spectra were recorded at $600 \mathrm{MHz}$ using a Bruker Avance AV-III-600 instrument. Chemical shift values are expressed in p.p.m. relative to tetramethylsilane. The following abbreviations or their combinations are used for the multiplicity of NMR signals: br, broad; d, doublet; m, multiplet; obs, obscured; s, singlet, sp, septet; t, triplet. LC-MS was run on a Waters Aquity UPLC-MS consisting of a column manager, a binary solvent manager, a sample organizer, a PDA detector (operating at $254 \mathrm{~nm}$ ), an ELS detector and an 
SQ-MS equipped with an APPI source operating in positiveion mode. The column was an Acquity UPLC BEH C18 $(1.7 \mu \mathrm{m}, 2.1 \times 50 \mathrm{~mm})$ operating at $60^{\circ} \mathrm{C}$ with a $1.2 \mathrm{ml} \mathrm{min}^{-1}$ binary gradient consisting of water $/ 0.1 \%$ formic acid (solvent $A$ ) and acetonitrile $/ 5 \%$ water $/ 0.1 \%$ formic acid (solvent $B$ ). The gradient changes between $10 \%$ solvent $B$ and $99.9 \%$ solvent $B$ over the 1 min run.

\subsection{Chiral supercritical fluid chromatography}

Chiral supercritical fluid chromatography (SFC) was run on an Aurora Fusion A5 unit together with Agilent 1100/1260 modules using a Phenomenex Lux 3u Cellulose-2 column, 4.6 $\times 250 \mathrm{~mm}$, flow $3 \mathrm{ml} \mathrm{min}^{-1}$ under $15 \mathrm{MPa}$ pressure at $40^{\circ} \mathrm{C}$. Ethanol and $0.1 \%$ diethylamine were used as modifiers at $20 \%$ concentration and UV detection operated at 254 and $230 \mathrm{~nm}$. In order to demonstrate that the compounds were enantiomerically pure, AF40431 and $\mathbf{1 h}$ were separately treated with TMS- $\mathrm{CH}_{2} \mathrm{~N}_{2}$ in THF to afford the corresponding methyl esters with identical NMR spectra: ${ }^{1} \mathrm{H}$ NMR $\left(\mathrm{CDCl}_{3}, 600 \mathrm{MHz}\right.$, TMS) $\delta: 7.43-7.41(1 \mathrm{H}, \mathrm{d}, J=8.5 \mathrm{~Hz}), 6.81-6.79(1 \mathrm{H}, \mathrm{d}, J=$ $8.5 \mathrm{~Hz}), 6.08(1 \mathrm{H}, \mathrm{d}, J=1.1 \mathrm{~Hz}), 4.37-4.34(1 \mathrm{H}, \mathrm{d}, J=14.1 \mathrm{~Hz})$, 4.11-4.07 (1H, d, $J=14.1 \mathrm{~Hz}), 3.87(3 \mathrm{H}, \mathrm{s}), 3.42-3.38(1 \mathrm{H}, \mathrm{m})$, $2.39-2.38(3 \mathrm{H}, \mathrm{d}, J=1.2 \mathrm{~Hz}), 1.79-1.71(1 \mathrm{H}, \mathrm{sp}, J=6.8 \mathrm{~Hz})$, $1.58-1.55$ (2H, obs m), 0.95-0.94 (3H, d, $J=6.8 \mathrm{~Hz}), 0.93-0.92$ $(3 \mathrm{H}, \mathrm{d}, J=6.8 \mathrm{~Hz})$. Mass spectrum: $\mathrm{tR}=0.45 \mathrm{~min}, \mathrm{~m} / z=334.1$ $(M+\mathrm{H})^{+}$. These methyl esters were submitted to chiral SFC both in their pure forms and as a 1:1 mixture of enantiomers. The pure sample of the methyl ester derivatives of AF40431 and $\mathbf{1 h}$ displayed unique retention times $(\mathrm{tR}=2.85$ and 3.34 min, respectively) by chiral SFC, while two distinct signals were observed for the mixed sample ( $\mathrm{tR}=2.84$ and $3.33 \mathrm{~min})$. As the homochiral starting materials L- and D-leucine afforded the homochiral products AF40431 and $\mathbf{1 h}$, respectively, it can be inferred that AF40431 has the $(S)$ absolute configuration of L-leucine; as to not do so would have required complete stereochemical inversion during one of the chemical transformations, which would be both highly unlikely and unprecedented for these transformations. The absolute configuration of AF40431 was not unambiguously characterized.

\subsection{Sortilin expression and purification}

The open reading frame of human sortilin including the endogenous signal peptide to residue 723 was amplified by PCR and cloned into the pCEP-pu vector with $X b a \mathrm{I}$ and $X$ XhoI. The primers were designed to include a C-terminal factor Xa site followed by a hexahistidine tag. HEK293F cells were transfected with $900 \mu \mathrm{g}$ plasmid, applying $900 \mu \mathrm{l}$ FreeStyle MAX reagent (Invitrogen) according to the manufacturer's instructions, and were grown in $900 \mathrm{ml}$ FreeStyle 293 medium (Invitrogen) in a 31 Erlenmeyer flask for $7 \mathrm{~d}$. The medium was harvested by centrifugation at $3700 \mathrm{~g}$ for $15 \mathrm{~min}$, filtered through a $0.40 \mu \mathrm{m}$ filter and the $\mathrm{pH}$ was adjusted by supplementation with Tris- $\mathrm{HCl} \mathrm{pH} 8.0$ to a final concentration of $50 \mathrm{~m} M$. A $5 \mathrm{ml} \mathrm{Ni-NTA} \mathrm{column} \mathrm{(GE} \mathrm{Healthcare)} \mathrm{was}$ equilibrated in buffer $A(50 \mathrm{~m} M$ Tris- $\mathrm{HCl} \mathrm{pH} 8.0,150 \mathrm{~m} M$ $\mathrm{NaCl}$ ) and the medium was recirculated over the column overnight. The column was washed with five column volumes of wash buffer $(50 \mathrm{~m} M$ Tris- $\mathrm{HCl} \mathrm{pH} 8.0,150 \mathrm{mM} \mathrm{NaCl}$, $10 \mathrm{~m} M$ imidazole) and sortilin was eluted with a ten-columnvolume imidazole gradient (10-250 $\mathrm{m} M$ imidazole). Fractions containing sortilin were pooled and concentrated by ultracentrifugation (Vivaspin 20, $10 \mathrm{kDa}$ cutoff, Sartorius). The sortilin was applied onto a Superdex 200 10/300 GL column (GE Healthcare) equilibrated in buffer $A$. Fractions containing sortilin were pooled, concentrated to a final concentration of $5 \mathrm{mg} \mathrm{ml}^{-1}$, flash-frozen in liquid nitrogen and stored at $-80^{\circ} \mathrm{C}$.

\subsection{Scintillation proximity assay}

The compound affinity was determined by measuring the displacement of ${ }^{3} \mathrm{H}$-neurotensin binding to sortilin using a scintillation proximity assay (SPA). Experiments were performed in assay buffer (50 $\mathrm{m} M$ HEPES $\mathrm{pH} 7.4,100 \mathrm{~m} M$ $\mathrm{NaCl}, 2.0 \mathrm{~m} M \mathrm{CaCl}_{2}, 0.1 \%$ BSA, $0.1 \%$ Tween-20) with a total volume of $40 \mu \mathrm{l}$. The compound was pre-incubated for $30 \mathrm{~min}$ at room temperature with $150 \mathrm{n} M$ sortilin before $5 \mathrm{n} M$ ${ }^{3} \mathrm{H}$-neurotensin and Ni-chelate imaging beads (Perkin Elmer) were added. After $6 \mathrm{~h}$, the plate was read on a ViewLux with $360 \mathrm{~s}$ exposure time. Unlabelled neurotensin and a DMSO blank were used as positive and negative controls, respectively. Dose-response evaluation of compounds was performed with ten concentrations of $\mathbf{1 a}-\mathbf{1 h}$ and AF40431 (covering concentrations between $2.5 \mathrm{n} M$ and $50 \mu M)$. The half-maximal inhibitory concentration $\left(\mathrm{IC}_{50}\right)$ values were calculated by nonlinear regression using the sigmoid concentration response (variable slope) in XLfit 4 (IDBS, UK). All values reported are the averages of at least four determinations.

\subsection{Isothermal titration calorimetry}

The binding of AF40431 to sortilin was measured by isothermal titration calorimetry (ITC). The titration experiments were performed on a MicroCal iTC200 isothermal titration calorimeter (MicroCal, Northampton, Massachusetts, USA). Sortilin was dialysed against PBS buffer $\mathrm{pH}$ 7.4. AF40431 was dissolved in PBS buffer pH 7.4 supplemented with $4 \%(v / v)$ dimethyl sulfoxide (DMSO). All solutions were filtered and degassed to avoid bubble formation and were equilibrated to the corresponding temperature before each experiment. Sortilin $(30 \mu M)$ supplemented with $4 \%(v / v)$ DMSO was titrated at $25^{\circ} \mathrm{C}$ with AF40431 $(500 \mu M)$ in 20 steps of $2 \mu \mathrm{l}$ (first step, $0.4 \mu \mathrm{l}$ ). The time between injections was set to $150 \mathrm{~s}$ and the syringe mixing speed was set to $1000 \mathrm{rev} \mathrm{min}^{-1}$. Heat evolving from dilution was measured by injecting the ligand into PBS supplemented with $4 \%$ DMSO. This heat was subtracted from the heat of reaction to obtain the effective heat of binding. Finally, the binding stoichiometry $(n)$, equilibrium dissociation constant $\left(K_{\mathrm{d}}\right)$, molar enthalpy and entropy changes for the binding processes were determined by analyzing the titration data using Origin software (OriginLab, Northampton, Massachusetts, USA). 


\subsection{AF40431 fluorescence spectroscopy}

AF40431 and sortilin were diluted in PBS buffer pH 7.4 to a final concentration of $0.1 \mu M$. Fluorescence was recorded on a RF-5301PC spectrofluorophotometer (Shimadzu) maintained at $23 \pm 1^{\circ} \mathrm{C}$ using 3 and $5 \mathrm{~nm}$ excitation and emission slit widths, respectively. The excitation and emission wavelengths were determined by scanning the ranges $250-430$ and 370$600 \mathrm{~nm}$, respectively.

\subsection{Sortilin crystallization, data collection and refinement}

Initial screening was performed using in-house polyethylene glycol (PEG) screens designed with the Mimer spreadsheet (Brodersen et al., 2013). Sortilin was preincubated with a ten-molar excess of AF40431 for 1 h. $200 \mathrm{nl}$<smiles>[R]C(NCc1c(O)ccc2c(C)cc(=O)oc12)C(=O)O</smiles>

\begin{tabular}{|c|c|c|c|}
\hline Compound & $R$ & $R$ & $\mathrm{IC}_{50}(\mu M)$ \\
\hline $1 a$ & $\mathrm{CH}_{2}{ }^{\mathrm{i}} \mathrm{Pr}$ & & $1.8 \pm 0.8$ \\
\hline $1 b$ & $\mathrm{CH}(\mathrm{Me}) \mathrm{Et}$ & & $6.1 \pm 2.7$ \\
\hline 1c & $\mathrm{Np}$ & & $3.1 \pm 1.1$ \\
\hline $1 d$ & c-Hex & & $1.7 \pm 0.3$ \\
\hline $1 e$ & iPr & & $>50$ \\
\hline $1 f$ & $\mathrm{Me}$ & & $>50$ \\
\hline $1 \mathrm{~g}$ & $\mathrm{Bn}$ & & $>50$ \\
\hline
\end{tabular}

(a)
sortilin-AF40431 was mixed with $200 \mathrm{nl}$ reservoir solution using a Mosquito liquid-handling robot (TTP LabTech) and equilibrated against $100 \mu \mathrm{l}$ reservoir solution using the sittingdrop vapour-diffusion method at $292 \mathrm{~K}$. Several crystal hits were obtained and were further optimized by grid screening and varying the molar excess of AF40431 in 24-well crystallization plates. The best diffracting crystals were obtained with a 20-molar excess of AF40431 in 0.1 $M$ HEPES-Tris pH 7.3, $0.4 M$ sodium malonate, 26\%( $w / v)$ PEG 3350 (Hampton Research), $8 \%(v / v)$ glycerol. The crystals grew to dimensions of $200 \times 100 \times 50 \mu \mathrm{m}$ over two weeks. The crystals were mounted in LithoLoops (Molecular Dimensions) from the mother liquor, excess mother liquor was removed by gently touching the side of the well with the edge of the loop (Morth et al., 2007) and the crystals were flash-cooled in liquid $\mathrm{N}_{2}$. A complete single-wavelength $(\lambda=0.9 \AA)$ data set of 1100 oscillation images with $0.2^{\circ}$ oscillation was collected at $100 \mathrm{~K}$ on the X06DA (PXIII) beamline at the Swiss Light Source (SLS) using a PILATUS 2M-F detector (Dectris). The diffraction images were processed in $X D S$ (Kabsch, 2010) and the reflections were scaled in SCALA (Winn et al., 2011). Molecular replacement was performed with Phaser (McCoy et al., 2007) using a search model derived from the structure of sortilin in complex with neurotensin (PDB entry 3f6k; Quistgaard et al., 2009). Rigid-body refinement, generation of ligand coordinates and restraints, calculation of OMIT maps and refinement were performed in PHENIX (Adams et al., 2010). Model building and analysis was performed using Coot<smiles>Cc1cc(=O)oc2c(CN(CC(=O)O)CC(=O)O)c(O)ccc12</smiles>

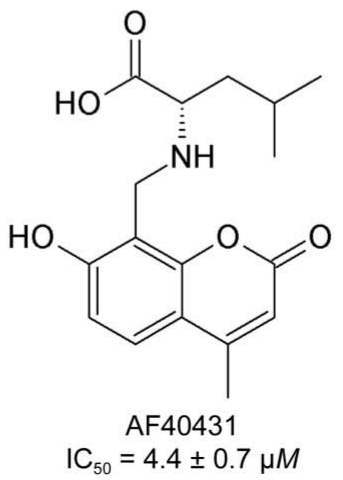

(b)<smiles>[M]OC1CN([R])CC(=O)O1</smiles><smiles>Cc1cc(=O)oc2c(CNC(CC(C)C)C(=O)O)c(O)ccc12</smiles>

(c)

Figure 1

Identification of AF40431. (a) Chemical structure and half-maximal inhibitory concentration ( $\mathrm{IC}_{50}$ ) values determined in the SPA assays of the hit compound $1 \mathbf{a}$ and its analogues $(\mathbf{1 b}-\mathbf{1 g})$. The stereochemistry of the samples in the compound collection was undefined $[i . e .(+),(-)$ or $( \pm)]$. $(b)$ Chemical structure of Calcein Blue (left) and tridentate metal (M) chelation by Calcein Blue (right). (c) Chemical structure and $\mathrm{IC}_{50}$ values determined from the SPA assay of AF40431 and its stereoisomer 1h. Chemical structure were drawn using ChemSketch (ACD/Labs; http://www.acdlabs.com). 
Table 1

Data-collection and refinement statistics for the sortilin-AF40431 complex.

Values in parentheses are for the highest resolution shell.

\begin{tabular}{|c|c|}
\hline \multicolumn{2}{|l|}{ Data collection } \\
\hline Space group & $C 2$ \\
\hline Unit-cell parameters $\left(\AA{ }^{\circ}{ }^{\circ}\right)$ & $\begin{array}{c}a=160.9, b=79.2, c=111.7, \\
\quad \beta=127.3\end{array}$ \\
\hline Resolution range $(\AA)$ & $47.0-2.7(2.85-2.70)$ \\
\hline No. of unique reflections & 30847 \\
\hline$R_{\text {merge }} \dagger(\%)$ & $4.5(54.9)$ \\
\hline$R_{\text {p.i.m }} \neq(\%)$ & $2.3(27.4)$ \\
\hline$\langle I / \sigma(I)\rangle$ & $19.0(2.3)$ \\
\hline Completeness (\%) & $99.9(99.7)$ \\
\hline Multiplicity & 3.9 \\
\hline Isotropic $B$ factor (Wilson) $\left(\AA^{2}\right)$ & 84.4 \\
\hline \multicolumn{2}{|l|}{ Refinement } \\
\hline Resolution range $(\AA)$ & $47.0-2.7$ \\
\hline No. of reflections & 30842 \\
\hline$R_{\text {work }} / R_{\text {free }} \S(\%)$ & $20.7 / 22.8$ \\
\hline \multicolumn{2}{|l|}{ No. of atoms } \\
\hline Protein (non-H) & 5143 \\
\hline AF40431 & 23 \\
\hline Glycosylations & 89 \\
\hline Water & 67 \\
\hline \multicolumn{2}{|l|}{$B$ factors $\left(\AA^{2}\right)$} \\
\hline Protein & 97.7 \\
\hline AF40431 & 63.3 \\
\hline Glycosylations & 106.6 \\
\hline Water & 65.9 \\
\hline \multicolumn{2}{|l|}{ R.m.s. deviations } \\
\hline Bond lengths $(\AA)$ & 0.011 \\
\hline Bond angles $\left({ }^{\circ}\right)$ & 1.260 \\
\hline \multicolumn{2}{|l|}{ Ramachandran plot, residues in (\%) } \\
\hline Most favoured region & 97.8 \\
\hline Allowed region & 2.2 \\
\hline Outlier region & 0.0 \\
\hline PDB code & $4 \mathrm{msl}$ \\
\hline
\end{tabular}

$\dagger R_{\text {merge }}=\sum_{h k l \mid} \sum_{i}\left|I_{i}(h k l)-\langle I(h k l)\rangle\right| / \sum_{h k l} \sum_{i} I_{i}(h k l)$, where $I_{i}(h k l)$ is the intensity of the $i$ th observation and $\langle I(h k l)\rangle$ is the mean intensity of reflection $h k l$. $\ddagger R_{\text {pi.m. }}=$ $\sum_{h k l}\{1 /[N(h k l)-1]\}^{1 / 2} \sum_{i}\left|I_{i}(h k l)-\langle I(h k l)\rangle\right| / \sum_{h k l} \sum_{i} I_{i}(h k l)$, where $N(h k l)$ is the multiplicity of reflection $h k l$. $\& R=\sum_{h k l}|| F_{\text {obs }}|-| F_{\text {calc }}|| / \sum_{h k l}\left|F_{\text {obs }}\right|$, where $F_{\text {obs }}$ and $F_{\text {calc }}$ are the observed and calculated structure factors, respectively.

(Emsley et al., 2010). The final model quality was analysed using MolProbity (score of 11.77; Chen et al., 2010). R.m.s.d. values were calculated, superpositions were performed and structural figures were prepared using PyMOL (Schrödinger; http://www.pymol.org).

\section{Results}

\subsection{Identification of AF40431}

Compound 1a, a promising hit with an $\mathrm{IC}_{50}$ of $1.8 \mu \mathrm{M}$ (Fig. 1a), was identified in a high-throughput screen of the $\mathrm{H}$. Lundbeck compound collection using the ${ }^{3} \mathrm{H}$-neurotensinbinding sortilin scintillation proximity assay (SPA). 1a is closely related to the dye Calcein Blue (Fig. $1 b$ ) and could thus potentially cause assay interference by fluorescence. Furthermore, molecules of the general type $\mathbf{1}$ have been reported (Wilkins, 1960) to ligate metals via a tridentate binding interaction (compound 2; Fig. $1 b$ ), which could also potentially cause assay interference. However, screening of analogues of 1a revealed a promising structure-activity relationship, which was consistent with specific molecular recognition rather than chemical-mediated assay interference (Fig. 1a). Specifically, the activity was retained when the leucine-type side chain of 1a $\left(\mathrm{CH}_{2}{ }^{\mathrm{i}} \mathrm{Pr}\right)$ was exchanged to the isoleucine-type side chain of $\mathbf{1 b}[\mathrm{CH}(\mathrm{Me}) \mathrm{Et}]$, the neopentyl substituent of $\mathbf{1 c}$ or the cyclohexyl substituent of 1d. In contrast, the activity was ablated by either substitution with the more compact valineand alanine-type side chains of $\mathbf{1 e}\left({ }^{\mathrm{i}} \mathrm{Pr}\right)$ and $\mathbf{1 f}(\mathrm{Me})$,

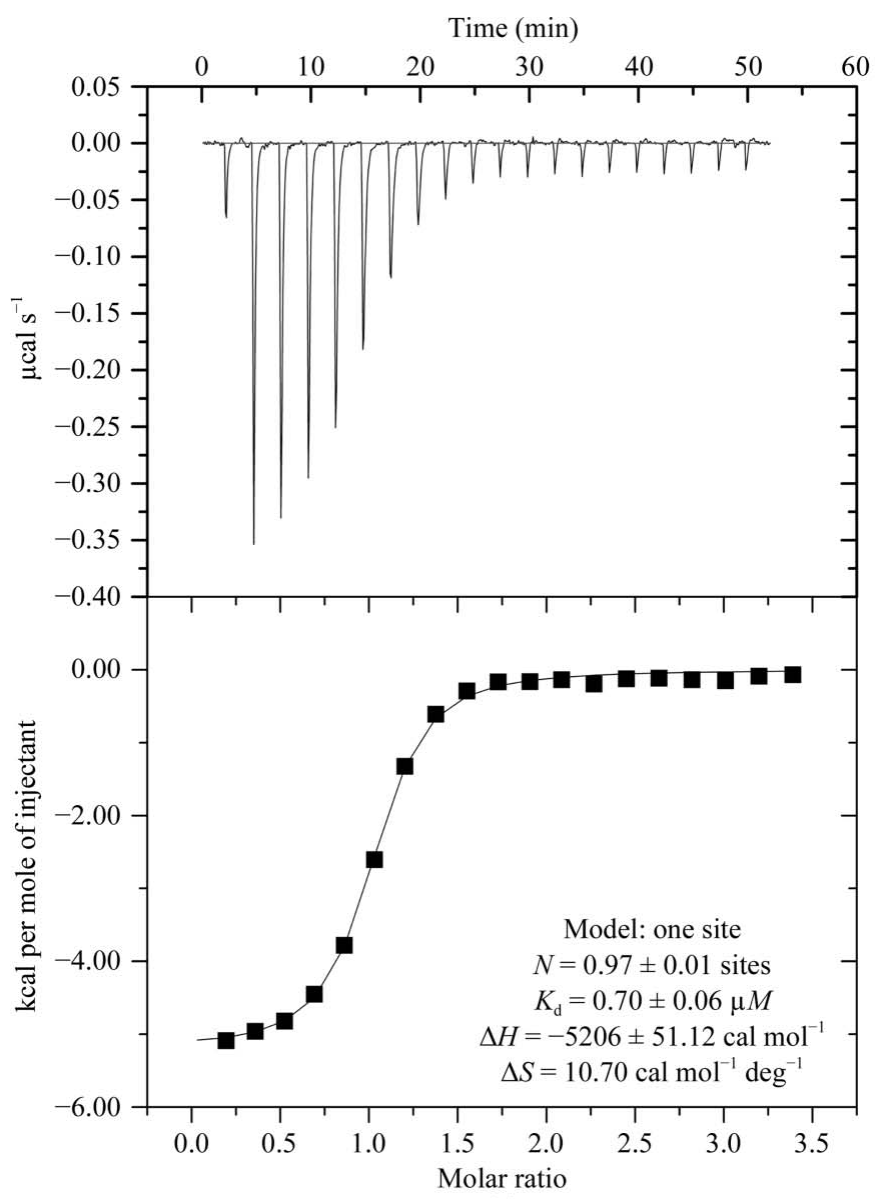

(a)

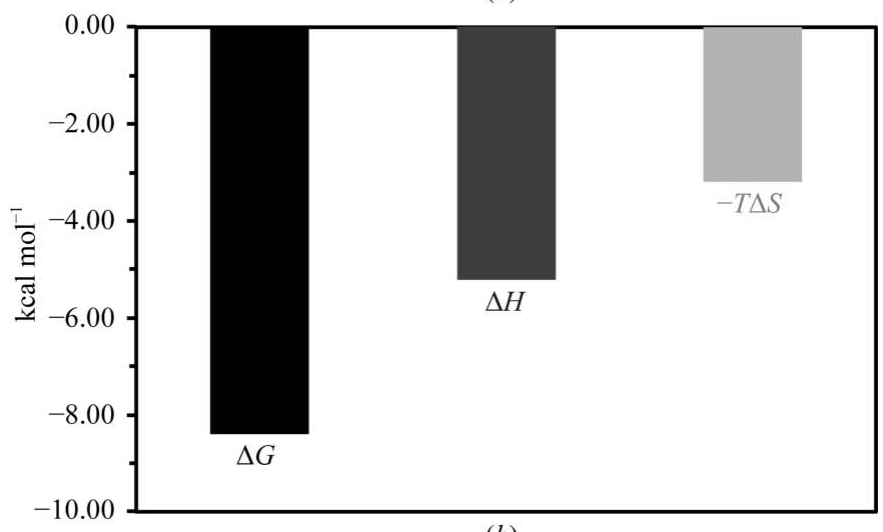

Figure 2

(b)

Thermodynamics of the binding of AF40431 to sortilin. (a) The raw titration data and the integrated titration curves are depicted in the upper and lower panels, respectively. The final values of the determined thermodynamic parameters are listed in the lower panel. (b) Binding signature plot listing the enthalpic $(\Delta H)$ and entropic $(-T \Delta S)$ contributions to the free binding energy $(\Delta G)$. 
respectively, or the bulkier phenylalanine-type side chain of $\mathbf{1 g}$ $(\mathrm{Bn})$. The stereochemistry of the samples in the compound collection (1a-1g) was undefined and therefore the influence of the stereochemistry on the activity was explored for 1a. The activity was found to reside in only one enantiomer, AF40431, whereas the corresponding antipode $\mathbf{1 h}$ was inactive (Fig. 1c). Such enantiospecific activity is consistent with a genuine molecular-recognition event with the target protein rather than assay interference, which would be expected to afford similar effects for both enantiomers. The activity of racemic sample 1a and the homochiral AF40431 were identical within experimental error. The binding of AF40431 to sortilin was furthermore confirmed by ITC with a dissociation constant $\left(K_{\mathrm{d}}\right)$ of $0.7 \mu M$ (Fig. $\left.2 a\right)$, and the free binding energy is driven by both enthalpic and entropic contributions (Fig. $2 b$ ). These structure-activity relationships gave us sufficient confidence in AF40431 to attempt co-crystallization with sortilin.

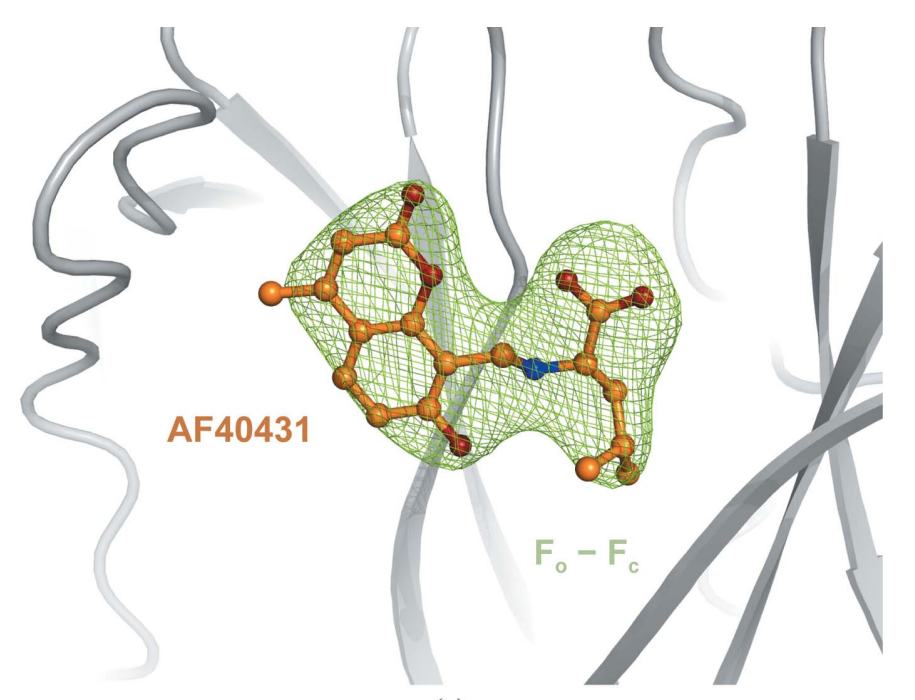

(a)

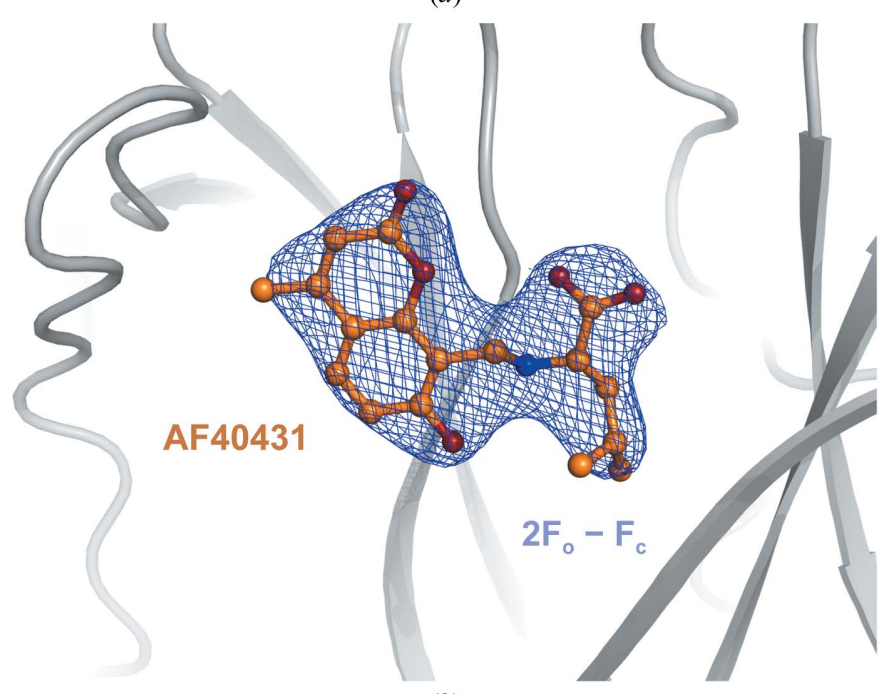

(b)

Figure 3

Electron-density maps of AF40431. (a) Bias-reduced simulated-annealing $F_{\mathrm{o}}-F_{\mathrm{c}}$ map contoured at the $3.0 \sigma$ level. (b) Final $2 F_{\mathrm{o}}-F_{\mathrm{c}}$ map contoured at the $1.5 \sigma$ level.

\subsection{Crystallization of the sortilin-AF40431 complex}

The extracellular Vps10p domain of sortilin was overexpressed in HEK293F cells and purified from the medium by immobilized metal-affinity chromatography. Sortilin was further purified by size-exclusion chromatography, eluting as a single symmetrical peak corresponding to monomeric sortilin. Crystals of the sortilin-AF40431 complex were obtained by co-crystallization. Initial crystallization hits were identified in an in-house polyethylene glycol (PEG) screen and were further optimized by grid screening and increasing the molar excess of AF40431. A complete data set was collected, scaling to a maximum resolution of $2.7 \AA$. The crystals of the sortilinAF40431 complex belonged to the monoclinic space group $C 2$, with unit-cell parameters $a=160.9, b=79.2, c=111.7 \AA$, $\beta=127.3^{\circ}$. The data statistics are summarized in Table 1 .

\subsection{Structure determination of the sortilin-AF40431 complex}

The atomic coordinates of the published sortilin-neurotensin complex structure (PDB entry 3f6k; Quistgaard et al., 2009), stripped of NTS, glycosylations and waters, was applied as a search model to obtain initial phases by molecular replacement (MR), yielding a translation-function $Z$-score (TFZ) of 66.5. The asymmetric unit was composed of a single molecule. The molecular-replacement solution was subjected to rigidbody and simulated-annealing refinement. Previously identified glycosylations (Quistgaard et al., 2009) were easily identified in the resulting bias-reduced $F_{\mathrm{o}}-F_{\mathrm{c}}$ electron-density maps, thereby validating the MR solution. Furthermore, additional density was observed in the NTS-binding site in the bias-reduced $F_{\mathrm{o}}-F_{\mathrm{c}}$ electron-density maps which remained during the building of glycosylations and subsequent rounds of

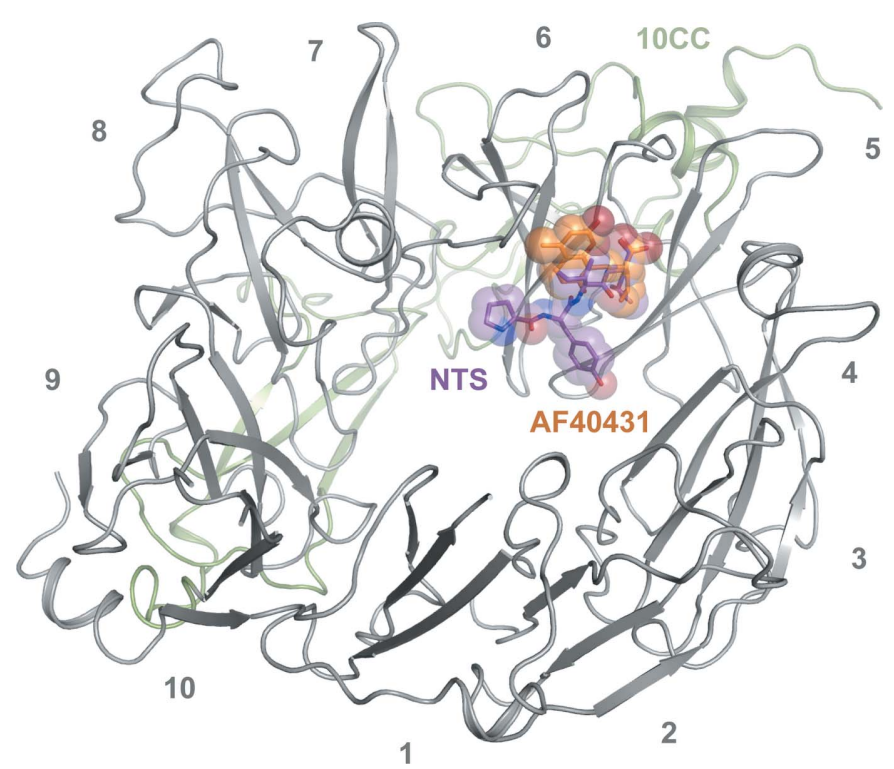

Figure 4

Overview of AF40431 binding to sortilin. The ten blades of the $\beta$-propeller and the 10CC domain are represented as grey and green cartoons, respectively. Neurotensin was superimposed from PDB entry 3f6k (Quistgaard et al., 2009) and is depicted as a purple ball-and-stick representation; AF40431 is depicted as orange sticks and spheres. 
refinement. Coordinates and geometric restraints were generated for AF40431, and the ligand could unambiguously be modelled into the density observed at the NTS-binding site. The structure was refined, resulting in good $R$ factors $\left(R_{\text {work }}\right.$ and $R_{\text {free }}$ of $20.7 \%$ and $22.8 \%$, respectively; Table 1 ). Binding of AF40431 was confirmed by bias-reduced simulatedannealing OMIT maps (Fig. $3 a$ ) and the density for AF40431 was well defined in the final $2 F_{\mathrm{o}}-F_{\mathrm{c}}$ maps (Fig. $3 b$ ).

\subsection{AF40431 binding to sortilin}

AF40431 is bound to sortilin in the centre of the tunnel of the $\beta$-propeller at the NTS-binding site (Fig. 4). The overall structure of the AF40431-sortilin complex resembled that of the NTS-sortilin complex (r.m.s.d. of $0.55 \AA$ for $\mathrm{C}^{\alpha}$ atoms), with the 10CC domain wrapped around the $\beta$-propeller. The leucine moiety of AF40431 is bound to sortilin in the same way

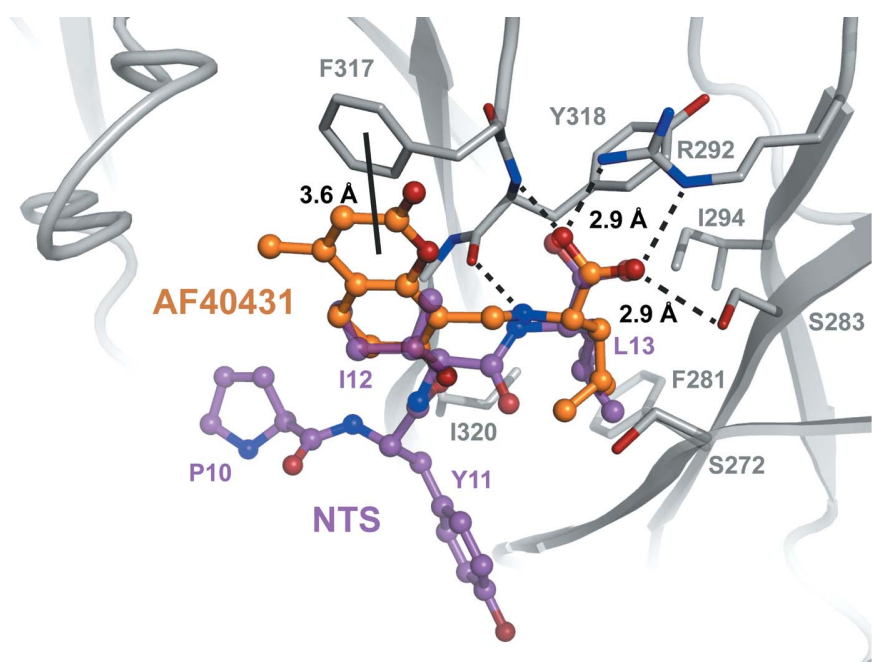

(a)

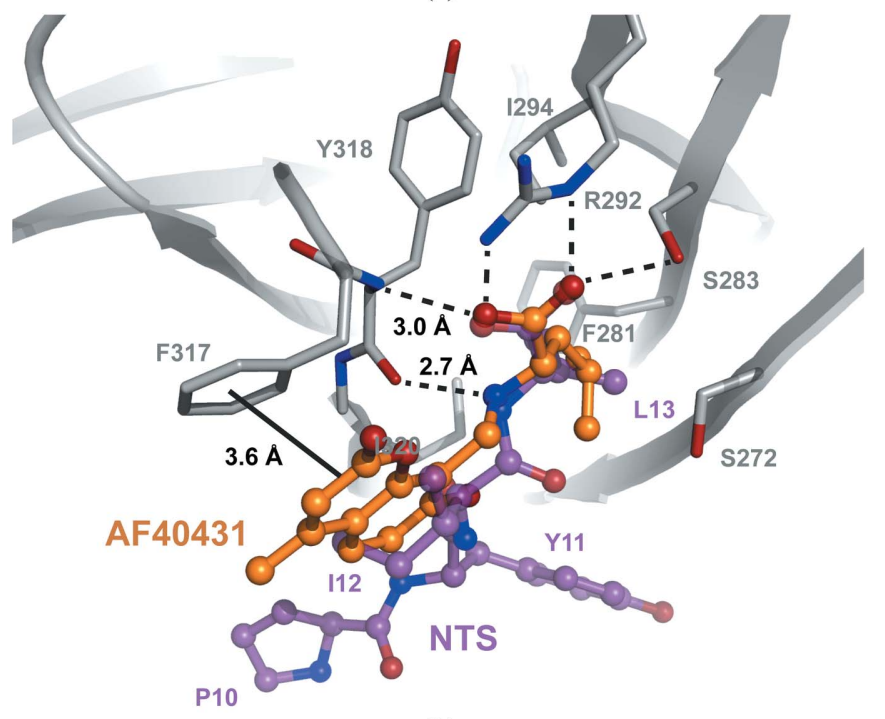

(b) as that of NTS, with the carboxylic acid forming a salt bridge to Arg292. The orientation of the carboxylic acid is further stabilized by hydrogen bonds to Ser283 and to the amide of Tyr318 (Fig. 5a). A hydrogen bond is formed between the secondary amine of AF40431 and the carbonyl of Tyr318 (Fig. 5b). The isopropyl group of AF40431 is buried in the hydrophobic pocket formed by Ser272, Phe281, Ile294 and Ile320, but is rotated $120^{\circ}$ compared with that of NTS. The 2-pyrone of the 4-methylumbelliferone moiety of AF40431 forms an off-centre parallel $\pi$-stacking interaction with Phe317 (Fig. 5b).

\section{Discussion}

A promising hit, compound 1a, was identified from the $\mathrm{H}$. Lundbeck compound collection by screening the displacement of ${ }^{3} \mathrm{H}$-NTS binding to sortilin in a scintillation proximity assay. We were initially suspicious of the activity of $\mathbf{1 a}$ and were concerned that the hit could be spurious owing to assay interference resulting from some potentially problematical structural features of the molecule. A structural alert against the pan assay interference compounds (PAINS) filters for assay interference is triggered by molecules of type $\mathbf{1}$ owing to their potential to undergo a retro-Mannich reaction and liberate reactive species (Baell \& Holloway, 2010). However, a sound structure-activity relationship was identified for six analogues of $\mathbf{1 a}(\mathbf{1 b}-\mathbf{1 g})$. Some variation in the length and size of the $\alpha$-alkyl substituent of $\mathbf{1 a}$ was allowed (1b-1d), whereas smaller (1e and 1f) and larger (1g) substituents ablated activity (Fig. 1a). The activity of 1a was shown to be enantiospecific, with all activity residing in a single enantiomer, namely AF40431, whereas the corresponding antipode $\mathbf{1 h}$ was inactive (Fig. 1c). The direct binding of AF40431 to sortilin was confirmed by ITC. The observed $K_{\mathrm{d}}(0.70 \mu M)$ is fivefold

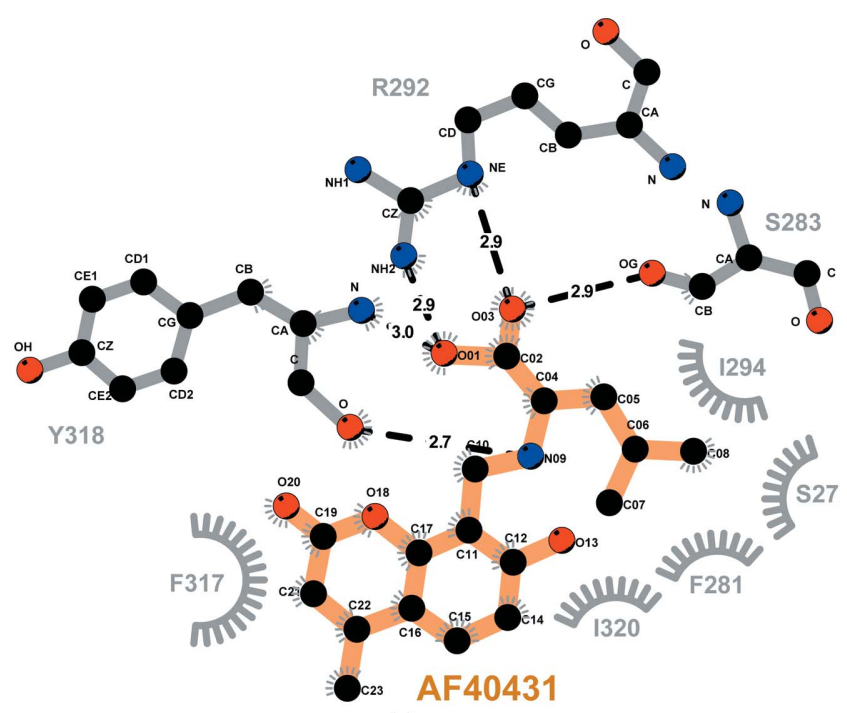

(c)

Figure 5

Binding mode of AF40431 to sortilin. $(a, b)$ Sortilin is represented as a cartoon in grey and the residues interacting with AF40431 are represented as sticks. C atoms of sortilin, AF40431 and NTS are depicted in grey, orange and purple, respectively, and N and O atoms are depicted in blue and red, respectively. (c) Schematic diagram of hydrogen bonds (black punctured lines) and hydrophobic interactions (grey arches with spokes) between AF40431 and sortilin prepared in LigPlot $^{+}$(Laskowski \& Swindells, 2011). 
higher than the $K_{\mathrm{d}}$ of NTS $(0.15 \mu M)$, with the higher affinity of NTS originating from the hydrogen bond between Tyr11 of NTS and Lys227 of sortilin (Quistgaard et al., 2009) and from contributions from the N-terminal region of NTS to binding (Quistgaard, 2014).

Crystals of the AF40431-sortilin complex were obtained by co-crystallization. A complete data set scaling to $2.7 \AA$ resolution was collected and the structure was solved by molecular replacement. Despite belonging to the same space group as the sortilin-NTS complex structure, a different packing of the

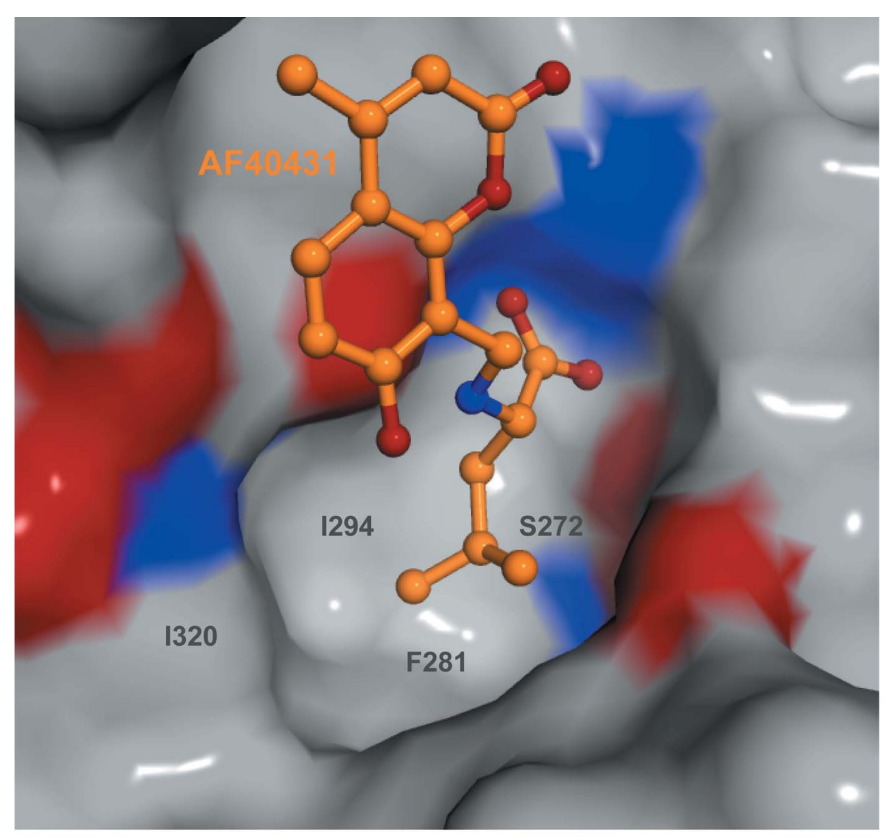

(a)

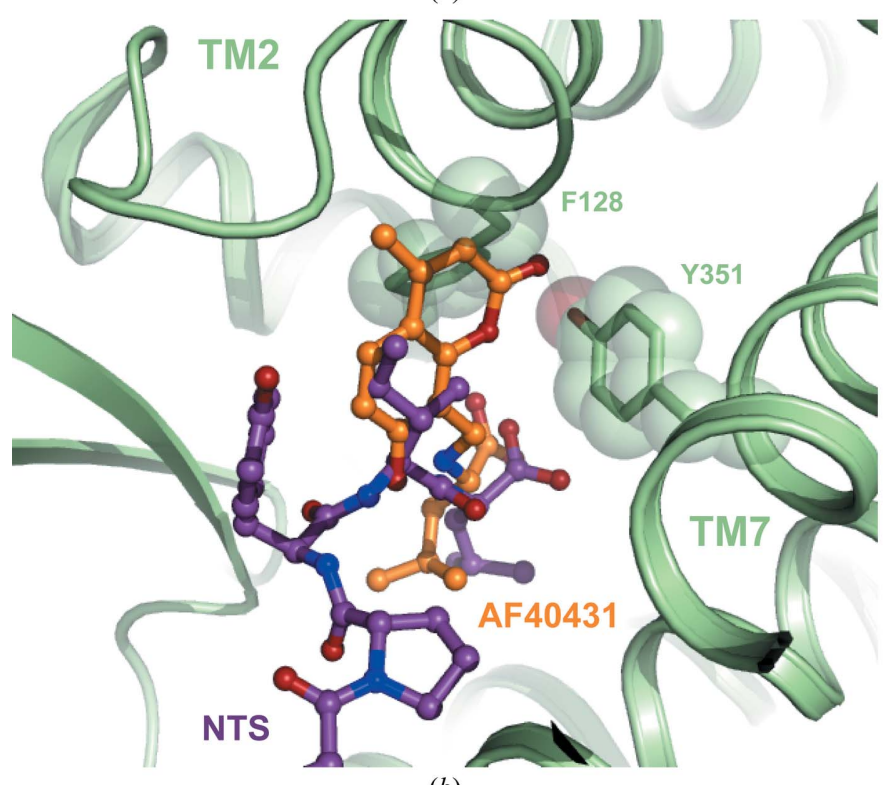

(b) molecules (Supplementary Fig. S1), similar to that of the selenomethionine-derivative and heavy-metal-derivative crystals of the sortilin-NTS complex, was observed (Quistgaard et al., 2009). AF40431 is bound to sortilin at the NTSbinding site and the leucine moiety of the ligand is bound to sortilin in the same way as the leucine of NTS (Fig. 4).

Overall, the binding of AF40431 to sortilin is driven by four components: electrostatic interaction and hydrogen bonds between the carboxylic acid of AF40431 and Arg292, Ser283 and Tyr318, a hydrogen bond between the secondary amine of AF40431 and the carbonyl of Tyr318, hydrophobic interactions between the isopropyl group and Ser272, Phe281, Ile294 and Ile320, and $\pi$-stacking between the 2-pyrone and Phe317 (Fig. 5c). The observed interactions are in good agreement with the free binding energy being driven by both enthalpic (electrostatic and hydrogen-bond interactions) and entropic (hydrophobic interaction) contributions (Fig. 2b).

The selective stereochemistry of AF40431 is defined by the hydrogen bond between the secondary amine of AF40431 and the carbonyl of Tyr318, the electrostatic interaction with Arg292 and the hydrophobic interaction of the isopropyl group. The simultaneous interaction with these three components is excluded by the stereochemistry of $\mathbf{1 h}$ (Fig. 5).

The structure-activity relationships obtained in the NTS scintillation proximity assay can be explained well by the size of the leucine-binding pocket of sortilin. The width of the pocket is determined by Ser272, Ile294 and Ile320, whereas the depth is determined by Phe281, which forms the 'floor' of the pocket (Fig. $6 a$ ). The pocket allows substitutions of similar size, namely the isoleucine-type side chain of $\mathbf{1 b}[\mathrm{CH}(\mathrm{Me}) \mathrm{Et}]$ and the neopentyl and cyclohexyl substituents of $\mathbf{1 c}$ and $\mathbf{1 d}$, respectively. The smaller isopropyl and methyl substituents of 1e and 1f, respectively, would not be expected to reach into the hydrophobic pocket and the bulkier benzyl substituent of $\mathbf{1 g}$ $\left(\mathrm{CH}_{2} \mathrm{Ph}\right)$ would be expected to sterically clash with the 'floor' formed by Phe281 (Fig. 6b).

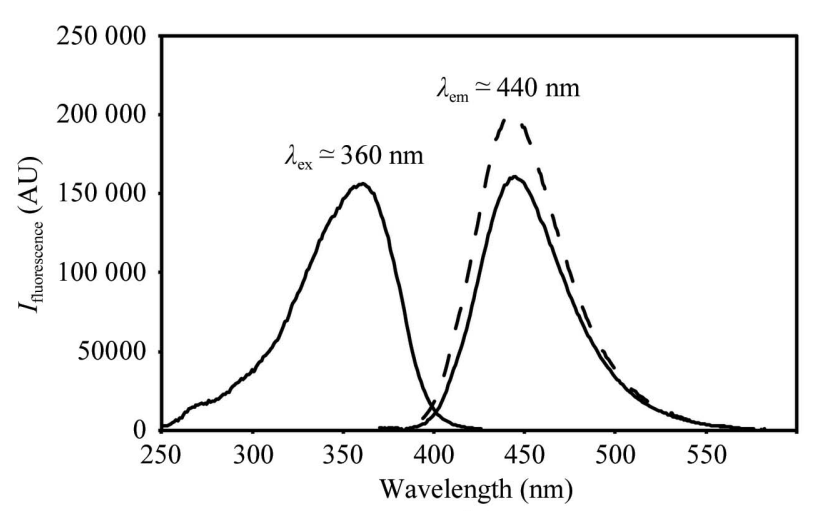

(c)

Figure 6

(a) The hydrophobic leucine-binding pocket. Sortilin is represented as a surface and is coloured according to atom type (C, N and $\mathrm{O}$ atoms in grey, blue and red, respectively). AF40431 is shown as a ball-and-stick representation in orange. The depth of the hydrophobic pocket is determined by Ser272, Phe281, Ile294 and Ile320. (b) Superposition of AF40431 and NTS in the structure of the NTSR1-NTS complex (PDB entry 4grv) represented as a cartoon in green (White et al., 2012). The 4-methylumbelliferone moiety of AF40431 clashes with Phe128 in TM2 and Tyr351 in TM7. (c) Combined excitation and emission fluorescence spectrum for AF40431 (full lines) and the sortilin-AF40431 complex (dotted lines). 
The phenol group of the 4-methylumbelliferone moiety of AF40431 is located in the position corresponding to that of Ile12 of NTS in the sortilin-NTS complex (Figs. $5 a$ and $5 b$ ) and, similar to Ile12, the phenol does not seem to contribute to the binding (Quistgaard et al., 2009). A parallel $\pi$-stacking interaction is formed between the 2-pyrone of the 4-methylumbelliferone moiety of AF40431 and sortilin. An off-centre stacking is caused by the two electron-rich systems of 2-pyrone and Phe281 (Hunter \& Sanders, 1990). The hydroxyl, ketone and methyl groups of 4-methylumbelliferone are not involved in interactions with sortilin and hence the structure-activity relationship should be explored for this two-ring system.

NTS binds to G-coupled neurotensin receptors (NTSRs) via amino acids 8-13, with the C-terminal leucine forming an electrostatic interaction with an arginine in the binding site (White et al., 2012). Hence, off-target reactions of AF40431 with the NTSRs could be expected. However, the Ile12 pocket of NTSR1 is narrow and steric clashes between the 4-methylumbelliferone moiety of AF40431 and Phe128 of transmembrane helix 2 (TM2) and Tyr351 of TM7 in NTSR1 were identified when AF40431 was superimposed on NTS in the NTSR1-NTS complex structure (White et al., 2012; Fig. 6b). No competition of NTS binding to NTSR1 was observed for AF40431 ( $\mathrm{IC}_{50}>50 \mu M$; data not shown).

The Calcein Blue moiety has previously been applied as a tracer in cellular and tissue studies (O'Malley et al., 1999). The fluorescent property of Calcein Blue is retained in AF40431 and the fluorescence is not statically quenched by the $\pi$-stacking with Phe317 upon binding to sortilin (Fig. 6c). Hence, AF40431 could be applied as a molecular tracer of sortilin. The identification of AF40431 suggests that sortilin is ligandable by small molecules and thus provides a stimulus to further small-molecule ligand discovery efforts for sortilin.

We are grateful to Karen Marx for excellent technical assistance and to Claus Olesen (Department of Biomedicine, Aarhus University) for assistance with fluorescence measurements. We would like to thank the Swiss Light Source (Paul Scherrer Institute) and MAX-lab (Lund University) for providing data-collection facilities and for excellent support. Furthermore, we acknowledge support from the European Community's Seventh Framework Programme (FP7/20072013) under BioStruct-X (grant agreement No. 283570) and from DanScatt - the Danish Centre for the Use of Synchrotron X-ray and Neutron Facilities.

\section{References}

Adams, P. D. et al. (2010). Acta Cryst. D66, 213-221.

Baell, J. B. \& Holloway, G. A. (2010). J. Med. Chem. 53, 2719-2740.

Beattie, M. S., Harrington, A. W., Lee, R., Kim, J. Y., Boyce, S. L., Longo, F. M., Bresnahan, J. C., Hempstead, B. L. \& Yoon, S. O. (2002). Neuron, 36, 375-386.

Bibel, M., Hoppe, E. \& Barde, Y. A. (1999). EMBO J. 18, 616-622. Brodersen, D. E., Andersen, G. R. \& Andersen, C. B. F. (2013). Acta Cryst. F69, 815-820.

Bruno, M. A. \& Cuello, A. C. (2006). Proc. Natl Acad. Sci. USA, 103, 6735-6740.
Chen, V. B., Arendall, W. B., Headd, J. J., Keedy, D. A., Immormino, R. M., Kapral, G. J., Murray, L. W., Richardson, J. S. \& Richardson, D. C. (2010). Acta Cryst. D66, 12-21.

Dechant, G. \& Barde, Y. A. (2002). Nature Neurosci. 5, 1131-1136.

Demont, Y., Corbet, C., Page, A., Ataman-Önal, Y., ChoquetKastylevsky, G., Fliniaux, I., Le Bourhis, X., Toillon, R. A., Bradshaw, R. A. \& Hondermarck, H. (2012). J. Biol. Chem. 287, 1923-1931.

Emsley, P., Lohkamp, B., Scott, W. G. \& Cowtan, K. (2010). Acta Cryst. D66, 486-501.

Esposito, D., Patel, P., Stephens, R. M., Perez, P., Chao, M. V., Kaplan, D. R. \& Hempstead, B. L. (2001). J. Biol. Chem. 276, 32687-32695.

Fahnestock, M., Michalski, B., Xu, B. \& Coughlin, M. D. (2001). Mol. Cell. Neurosci. 18, 210-220.

Frade, J. M. \& Barde, Y.-A. (1999). Development, 126, 683-690.

Harrington, A. W., Leiner, B., Blechschmitt, C., Arevalo, J. C., Lee, R., Mörl, K., Meyer, M., Hempstead, B. L., Yoon, S. O. \& Giehl, K. M. (2004). Proc. Natl Acad. Sci. USA, 101, 6226-6230.

Hempstead, B. L., Martin-Zanca, D., Kaplan, D. R., Parada, L. F. \& Chao, M. V. (1991). Nature (London), 350, 678-683.

Hermans-Borgmeyer, I., Hermey, G., Nykjaer, A. \& Schaller, C. (1999). Brain Res. Mol. Brain Res. 65, 216-219.

Hunter, C. A. \& Sanders, J. K. M. (1990). J. Am. Chem. Soc. 112 , 5525-5534.

Jansen, P., Giehl, K., Nyengaard, J. R., Teng, K., Lioubinski, O., Sjoegaard, S. S., Breiderhoff, T., Gotthardt, M., Lin, F., Eilers, A., Petersen, C. M., Lewin, G. R., Hempstead, B. L., Willnow, T. E. \& Nykjaer, A. (2007). Nature Neurosci. 10, 1449-1457.

Kabsch, W. (2010). Acta Cryst. D66, 125-132.

Kjolby, M., Andersen, O. M., Breiderhoff, T., Fjorback, A. W., Pedersen, K. M., Madsen, P., Jansen, P., Heeren, J., Willnow, T. E. \& Nykjaer, A. (2010). Cell Metab. 12, 213-223.

Laskowski, R. A. \& Swindells, M. B. (2011). J. Chem. Inf. Model. 51, 2778-2786.

Lee, R., Kermani, P., Teng, K. K. \& Hempstead, B. L. (2001). Science, 294, 1945-1948.

Lu, B., Pang, P. T. \& Woo, N. H. (2005). Nature Rev. Neurosci. 6, 603-614.

Mazella, J., Zsürger, N., Navarro, V., Chabry, J., Kaghad, M., Caput, D., Ferrara, P., Vita, N., Gully, D., Maffrand, J. P. \& Vincent, J. P. (1998). J. Biol. Chem. 273, 26273-26276.

McCoy, A. J., Grosse-Kunstleve, R. W., Adams, P. D., Winn, M. D., Storoni, L. C. \& Read, R. J. (2007). J. Appl. Cryst. 40, 658-674.

Morth, J. P., Pedersen, B. P., Toustrup-Jensen, M. S., Sørensen, T. L., Petersen, J., Andersen, J. P., Vilsen, B. \& Nissen, P. (2007). Nature (London), 450, 1043-1049.

Munck Petersen, C., Nielsen, M. S., Jacobsen, C., Tauris, J., Jacobsen, L., Gliemann, J., Moestrup, S. K. \& Madsen, P. (1999). EMBO J. 18, 595-604.

Nielsen, M. S., Madsen, P., Christensen, E. I., Nykjaer, A., Gliemann, J., Kasper, D., Pohlmann, R. \& Petersen, C. M. (2001). EMBO J. 20, 2180-2190.

Nykjaer, A., Lee, R., Teng, K. K., Jansen, P., Madsen, P., Nielsen, M. S., Jacobsen, C., Kliemannel, M., Schwarz, E., Willnow, T. E., Hempstead, B. L. \& Petersen, C. M. (2004). Nature (London), 427, 843-848.

O'Malley, J. P., Waran, M. T. \& Balice-Gordon, R. J. (1999). J. Neurobiol. 38, 270-286.

Petersen, C. M., Nielsen, M. S., Nykjaer, A., Jacobsen, L., Tommerup, N., Rasmussen, H. H., Roigaard, H., Gliemann, J., Madsen, P. \& Moestrup, S. K. (1997). J. Biol. Chem. 272, 3599-3605.

Quistgaard, E. M. (2014). In preparation.

Quistgaard, E. M., Madsen, P., Grøftehauge, M. K., Nissen, P., Petersen, C. M. \& Thirup, S. S. (2009). Nature Struct. Mol. Biol. 16, 96-98.

Quistgaard, E. M. \& Thirup, S. S. (2009). BMC Struct. Biol. 9, 46.

Scott, J., Selby, M., Urdea, M., Quiroga, M., Bell, G. I. \& Rutter, W. J. (1983). Nature (London), 302, 538-540. 


\section{research papers}

Tauris, J., Gustafsen, C., Christensen, E. I., Jansen, P., Nykjaer, A., Nyengaard, J. R., Teng, K. K., Schwarz, E., Ovesen, T., Madsen, P. \& Petersen, C. M. (2011). Eur. J. Neurosci. 33, 622-631.

Teng, H. K., Teng, K. K., Lee, R., Wright, S., Tevar, S., Almeida, R. D., Kermani, P., Torkin, R., Chen, Z.-Y., Lee, F. S., Kraemer, R. T., Nykjaer, A. \& Hempstead, B. L. (2005). J. Neurosci. 25, 5455-5463.

Truzzi, F., Marconi, A., Lotti, R., Dallaglio, K., French, L. E., Hempstead, B. L. \& Pincelli, C. (2008). J. Invest. Dermatol. 128,
2031-2040.

White, J. F., Noinaj, N., Shibata, Y., Love, J., Kloss, B., Xu, F., Gvozdenovic-Jeremic, J., Shah, P., Shiloach, J., Tate, C. G. \& Grisshammer, R. (2012). Nature (London), 490, 508-513.

Wilkins, D. (1960). Talanta, 4, 182-184.

Winn, M. D. et al. (2011). Acta Cryst. D67, 235-242.

Wu, X., Daniels, T., Molinaro, C., Lilly, M. B. \& Casiano, C. A. (2002). Cell Death Differ. 9, 915-925. 